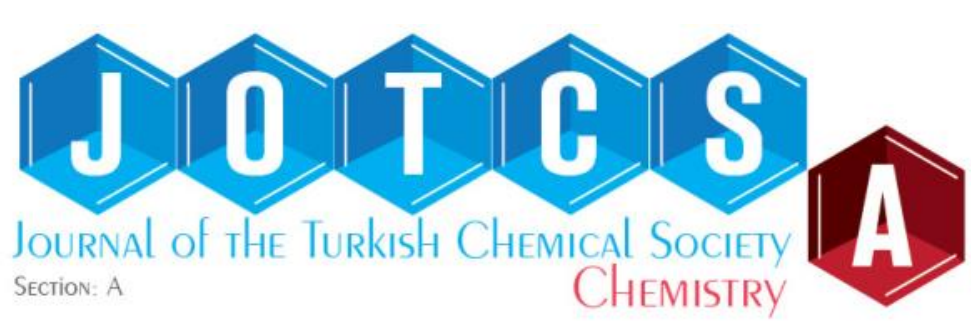

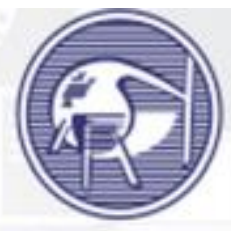

TURKISH

CHEMICAL SOCIETY

\title{
Corrosion-resistant hybrid coatings for copper surfaces substrates by sol-gel chemistry
}

\author{
Esin AKARSU ${ }^{1}$, Ömer KESMEZ ${ }^{1 *}$ \\ ${ }^{1}$ Science Faculty of Akdeniz University, 07058, Antalya, Turkey
}

(This manuscript was initially submitted to VI ${ }^{\text {th }}$ Inorganic Chemistry Congress on May 18-21 2017, Burdur, Turkey, and accepted by the JOTCSA editorial staff for publication)

\begin{abstract}
Corrosion is the degradation of a metal, which is caused by chemical reactions between the metal and its surroundings. It poses severe and inevitable problems to the longterm use of particularly copper-based materials in daily life due to the requirement of periodically replacement of it and the loss of its appearance. Therefore, it is necessary to apply a protective layer on them to extend the life span. In this study, inorganic-organic hybrid coatings comprising thiol functional silanes on copper sheets were obtained by spraying onto it followed by curing at elevated temperature. All coatings studied were optically transparent, smooth and crack-free. As they showed excellent adhesion to the copper surface, they were resistant to UV radiation and solutions of acidic and basic conditions. By the coating of copper sheets with hybrid coatings studied, both their mechanical durability and corrosion resistance in the salt spray test were considerably improved.
\end{abstract}

Keywords: Sol-Gel, Hybrid Coating, Transparent Thin Film, Corrosion-resistant materials.

Submitted: June 30, 2017. Accepted: November 27, 2017.

Cite this: Akarsu E, Kesmez Ö. Corrosion-resistant hybrid coatings for copper surfaces substrates by sol-gel chemistry. JOTCSA. 2017;4(sp. is. 1):65-76.

DOI: http://dx.doi.org/10.18596/jotcsa.324873.

*Corresponding author. E-mail: omerkesmez@akdeniz.edu.tr 


\section{INTRODUCTION}

Copper and copper alloys are one of the most multipurpose materials. They find extensive applications in diverse areas such as building industry, electronic products, transportation, consumer products, and industrial machinery because of the unique combination of characterics such as thermal and electrical conductivity, mechanical workability, antimicrobial effect, ductility and malleability. Although copper relatively is a stable metal, it still tends to corrode easily in chlorine-rich environments under high humidity conditions.

To prevent the corrosion of copper-based materials, two types of corrosion inhibitors are added into the corresponding medium (1): inorganic inhibitors $(2,3)$ such as salts of chromate, molybdate and tetraborate, and organic inhibitors such as azoles (4-7), amines, amino acids (812), imidazole and its derivatives, thiourea (13-15), 1-dodecanethiol, indole derivatives, and sodium heptanoate (16-17).

By applying a protective layer onto it, the corrosion resistance of copper can considerably be improved. In previous studies, it was found out that when self-assembled monolayers (SAMs) of alkanethiols (18) and triazoles (19) were deposited on copper surfaces, its corrosion resistance was improved due to the formation of an interface layer through a stable Cu-S bonding chemically. Sui et al. (20) have compared the effectiveness of SAMs alkylthiols to the silica coating obtained from the solution of hydrolyzed (3-mercaptopropyl) trimethoxysilane by solgel chemistry. Their investigations are concluded that the corrosion resistance of silica coating was superior to that of SAMs because of the additional barrier effect provided by $\mathrm{Si}-\mathrm{O}-\mathrm{Si}$ twodimensional network.

The sol-gel process is a chemical synthesis method where an alkoxide network is created by progressive condensation reactions of molecular precursors from a liquid medium. Organicinorganic hybrid coatings can be produced via sol-gel chemistry by the utilization of functional silanes comprising nonhydrolyzable $\mathrm{Si}-\mathrm{C}$ bonding. It has the advantage of the combination of the elastic behavior of the organic component (polymeric) with the stiffness of the inorganic (alkoxide) backbone (21).

The aim of this study was to develop an optically transparent, mechanically durable inorganicorganic hybrid coating with improved corrosion resistance for copper-based materials. In this study, thiol functional silane with different chemistries were applied not only as a SAMs layer (primary layer to the top-coat of hybrid coating) but also incorporated in inorganic-organic matrix synthesized by sol-gel chemistry to determine their impact on the corrosion resistance of copper. 


\section{MATERIALS AND METHODS}

\section{Chemicals and Equipment}

(3-mercaptopropyl) trimethoxysilane (GF70) and Bis-[3-(triethoxysilyl)-propyl]tetrasulfide (Si69), whose structures are shown in Figure 1, were purchased from Sigma Aldrich. The precursors were 3-(glycidyloxypropyl) trimethoxy silane (GLYMO, Evonik Industries AG) as a $\mathrm{SiO}_{x}$ source, ethylacetoacetate (HacacOEt, $\mathrm{ABCR}$ ) as complexing agent for aluminum-tri-secbutoxide ( $\mathrm{Al}\left(\mathrm{O}^{\mathrm{s}} \mathrm{Bu}\right)_{3}$, Merck Chemicals), 1-methoxy-2-propanol (PM, Sigma Aldrich) and ethylene glycol monobutyl ether (BG, Merck Chemicals), as solvents.

\section{b}
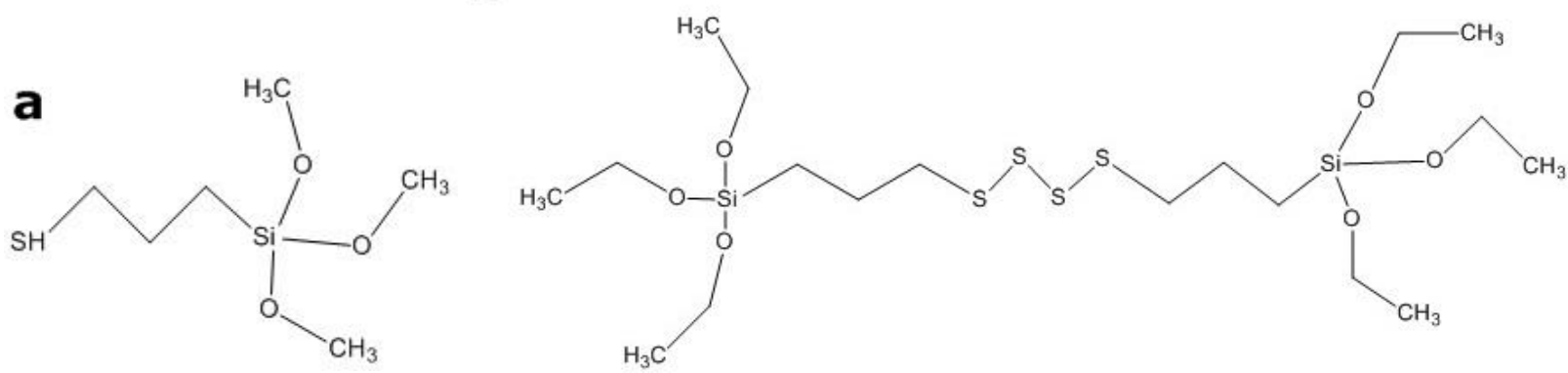

Figure 1: The structure of a. (3-mercaptopropyl) trimethoxysilane, b. Bis-[3-(triethoxysilyl)propyl]tetrasulfide.

A scanning electron microscope (QUANTA 400F Field Emission SEM) was used to determine surface morphology. The composition of the samples was analyzed by means of energy dispersive X-ray analysis (EDX). The aging of the coatings was carried out in a sun simulator (Erichsen, 1500 model). Surface hardness and adhesion of coatings were tested by an Erichsen Scratch Hardness Tester Model 291 / Erichsen Hardness Test Pencil, Model 318S and an Erichsen Type 295 multi-cross cutter, respectively. A spectrophotometer (X-Rite 962-964 model) was used to determine the color values of the coatings before and after treatment of the aging test. Salt spray tests were performed in a corrosion chamber (Erichsen, Corrotherm model 610) according to standard ISO 11503 . The optical properties of coatings were measured using a UVVis-NIR spectrophotometer (Varian Cary model 5000).

\section{Preparation of Coating Solution and Coated Surface}

The hybrid coating matrix was prepared at room temperature as follows: one mole of GLYMO was placed in a glass bottle and then one mole of water in form of $1 \mathrm{M}$ nitric acid solution was added into it with continuous stirring to pre-hydrolyze silane. The silane solution was aged keeping stirring further for two hours. Separately, one mole of HacacOEt was dropped into one mole of $\mathrm{Al}\left(\mathrm{O}^{\mathrm{s}} \mathrm{Bu}_{3}\right)$ under stirring and stirred further for one hour to obtain a 1:1 complex solution of aluminum alkoxide with HacacOEt (22). To finally obtain the hybrid coating matrix, the 1:1 complex solution was added drop wise into the silane solution under stirring and then kept stirring for further one hour (23). 
To prepare final top-coat, the used corrosion inhibitor (i.e. GF70 or Si69) was dropped into the hybrid coating matrix above under stirring, afterwards the remaining unreacted alkoxy groups on silane compounds were completely hydrolyzed with a solution of water and the 1:1 mixture by weight of PM and BG, in which the amount of water was two moles per mole silane. The final top-coat had a solid content of 30 percentages by weight and 2.5 percentages by weight of G70 or Si69 in the solid content.

To obtain the solutions of primary layers, each of G70 and Si69 was hydrolyzed with three moles of water per mole silane in presence of formic acid (FA, Merck Chemicals) as catalyst after diluting it with PM down to the solid content of $5 \%$ by weight.

To coat copper substrates, the solutions of were sprayed onto a sheet of copper substrate and then cured at $130{ }^{\circ} \mathrm{C}$ for 30 minutes in a convection oven. After cooling down to the room temperature, top-coats were applied by spraying onto the primered substrates followed by a heat treatment at $130{ }^{\circ} \mathrm{C}$ for 90 minutes. The thickness of the cured top-coat layers was about 5-8 $\mu \mathrm{m}$. The prepared samples were designed as shown in Table 1.

Table 1. The description of the obtained coated samples.

\begin{tabular}{ccc}
\hline Sample & Primer & Top - Coat \\
\hline 1A & - & Hybrid matrix+GF70 \\
1B & - & Hybrid matrix+Si69 \\
1C & - & Hybrid matrix \\
2A & GF70 Primer & Hybrid matrix+GF70 \\
2B & GF70 Primer & Hybrid matrix \\
2C & GF70 Primer & - \\
3A & Si69 Primer & Hybrid matrix+GF70 \\
3B & Si69 Primer & Hybrid matrix \\
3C & Si69 Primer & - \\
\hline
\end{tabular}

\section{Aging Test}

Transparent coatings on copper substrates were tested against UV irradiation to determine any color changes. The samples were exposed to UV irradiation $\left(1,000 \mathrm{~W} / \mathrm{m}^{2}\right)$ for 7 -days. And then, color data were measured before and after UV irradiation using an X-Rite 962-964 spectrophotometer. $\Delta E$ values are calculated by using the color data ( $L$ : level of light or dark; a: redness or greenness; $b$ : yellowness or blueness).

$$
E=\sqrt{\left[\left(L_{a}-L_{b}\right)^{2}+\left(a_{a}-a_{b}\right)^{2}+\left(b_{a}-b_{b}\right)^{2}\right]}
$$

\section{Mechanical and Adhesion Tests}

Surface hardness and adhesion of coatings were carried out by an Erichsen Scratch Hardness Tester Model 291 / Erichsen Hardness Test Pencil, Model 318S, an Erichsen Type 295 multicross cutter, respectively. The results of the tests were evaluated according to the ASTM D 3359 protocol (24). 


\section{Corrosion resistance and acid-base test}

The corrosion resistance of samples was determined by the salt spray test. With this test method, it is not possible to determine the mechanism and the type of occurring corrosion. But it allows correlating the results of the test to real-life applications, which is the ultimate method of testing in industry. In the salt spray test, coatings were kept in a medium which was sprayed continuously with $5 \%$ by weight of aqueous solution of sodium chloride solution in a closed system at $100 \%$ relative humidity. Surfaces of samples were examined visually after the test.

Coatings on copper surface was tested against different $\mathrm{pH}$ values by using a solution of $\mathrm{HNO}_{3}$ at $\mathrm{pH}=2$ and a solution of $\mathrm{NaOH}$ at $\mathrm{pH}=12$ utilizing Erichsen Corrosion Instrument Solvent Checker 434. In this test, solutions were kept in touch with the surface of the samples for one hour at room temperature. The surface of the tested sample was inspected visually.

\section{RESULTS AND DISCUSSION}

In Figure 2, SEM micrographs of coatings of samples $1 \mathrm{C}, 2 \mathrm{~A}$ and $3 \mathrm{~A}$ on copper sheets are shown. All coatings have a smooth surface. The surfaces are uniform and have no crack on them indicating spraying of coating solutions is a feasible method even for decorative applications.

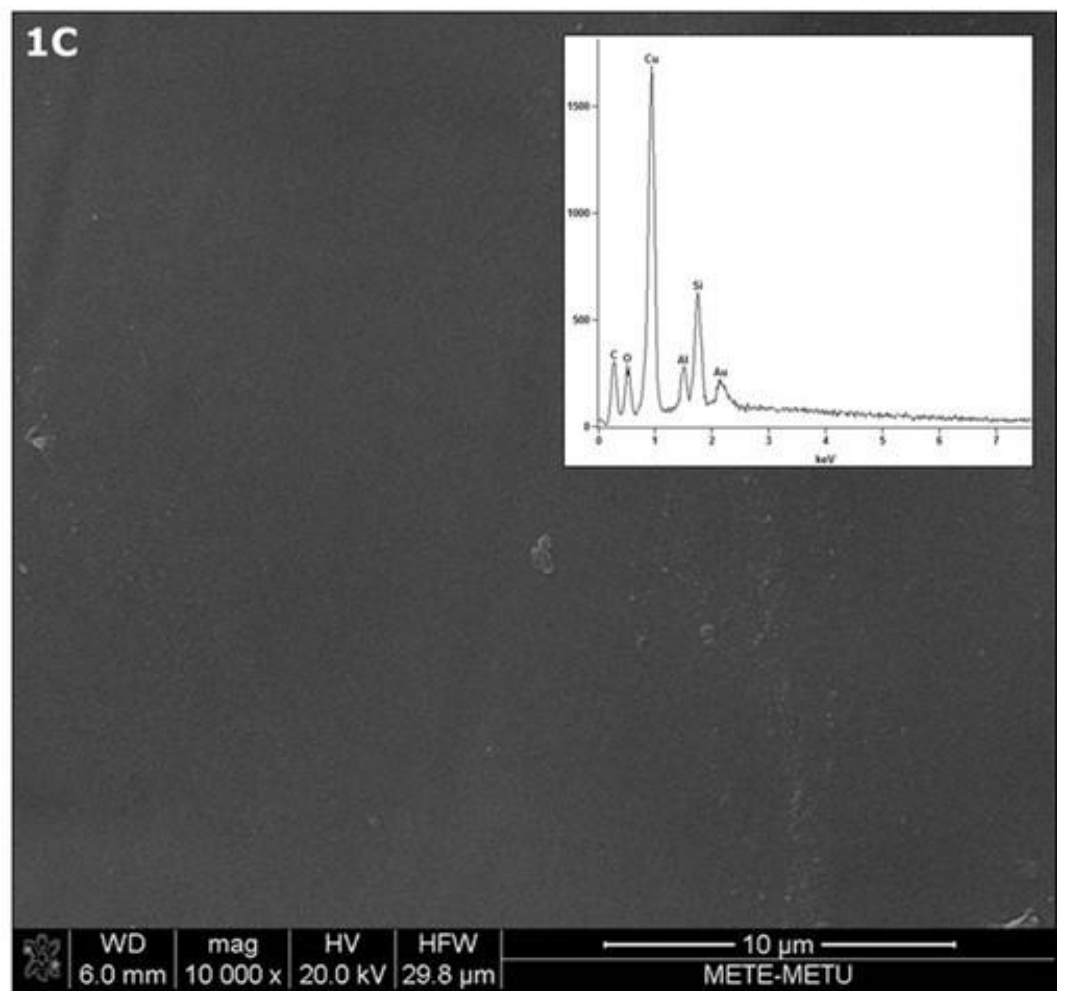



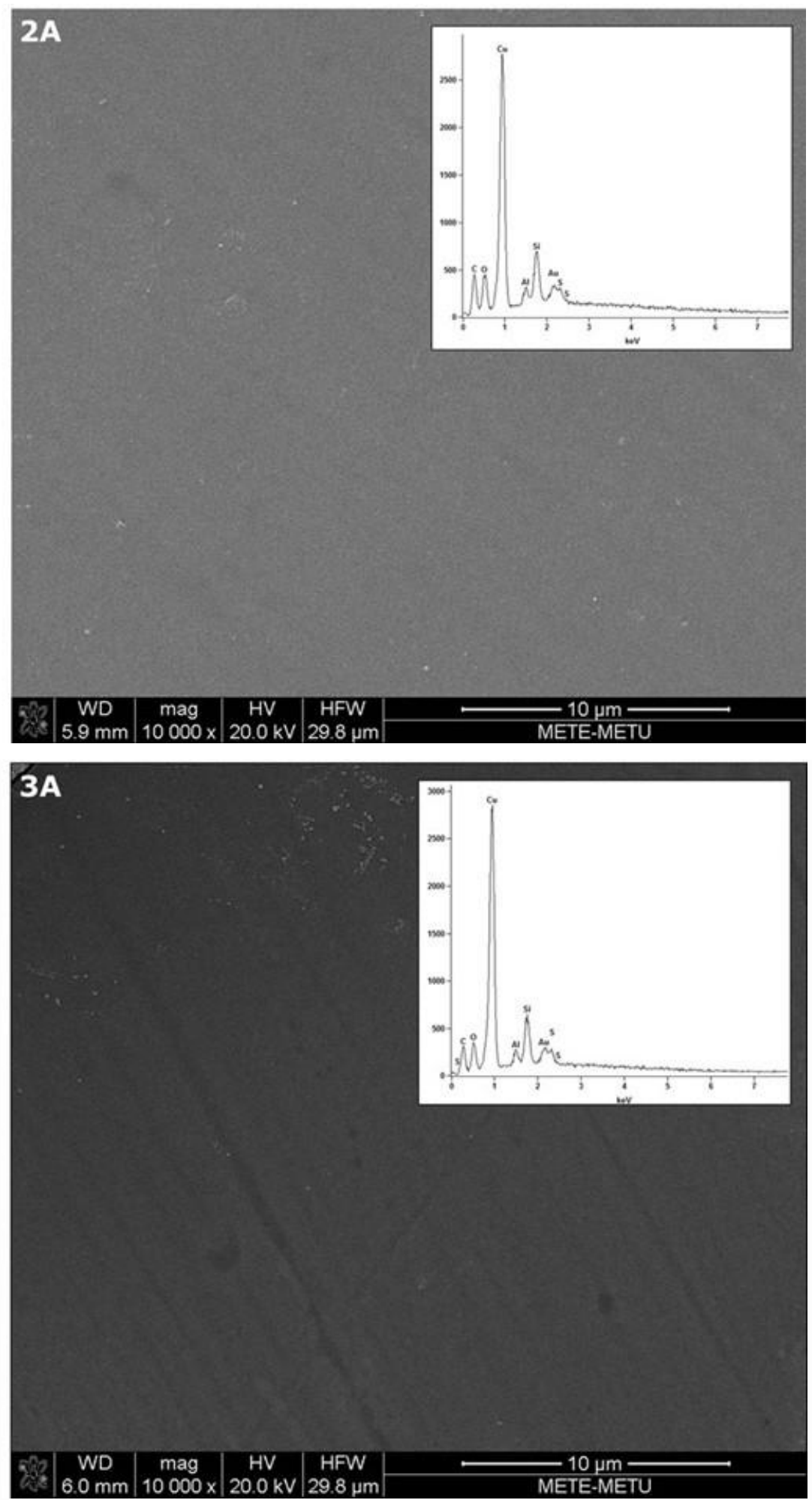

Figure 2: SEM images and spectra of EDX elemental analysis of coatings $1 \mathrm{C}, 2 \mathrm{~A}$ and $3 \mathrm{~A}$.

Elemental analysis by EDX was performed on the surface of coated samples. The ratios of Al, $\mathrm{Si}$ and $\mathrm{S}$ determined from the EDX analyses are in agreement with the theoretical composition of the coating layers. Additionally, the presence of copper detected in the EDX analyses is due to the penetration of high energy electrons down to the copper substrate. According to EDX results given in Table 1 , the detected amount of sulfur in coatings from $1 \mathrm{C}$ to $3 \mathrm{~A}$ increases in respect to the incorporated amount of the thiol groups on used functional silanes (3). 
Table 2: The results of elemental analysis by EDX for the coatings $1 \mathrm{C}, 2 \mathrm{~A}$ and $3 \mathrm{~A}$.

\begin{tabular}{c|ccc|c|c|c|c}
\hline \multirow{2}{*}{ Element } & \multicolumn{2}{|c|}{ 1C } & \multicolumn{2}{c|}{ 2A } & \multicolumn{2}{c}{ 3A } \\
\cline { 2 - 7 } & Weight \% & Atom \% & Weight \% & Atom \% & Weight \% & Atom \% \\
\hline \multirow{2}{*}{ SI } & 24.6 & 24.9 & 17.1 & 18.2 & 15.1 & 16.2 \\
S & 75.4 & 75.1 & 61.1 & 62.3 & 58.0 & 59.6 \\
\hline
\end{tabular}

The coordinates of color of samples $1 \mathrm{C}, 2 \mathrm{~A}$ and $3 \mathrm{~A}$ and their $\Delta \mathrm{E}$ values calculated from Equation 1 before and after solar irradiation are listed in Table 3. $\Delta \mathrm{E}$ value of less than 3 indicates that the change in color cannot be perceived by the naked eye. As the uncoated copper sheet was exposed to solar irradiation, its color noticeably changes, i.e. its $\Delta \mathrm{E}>>3$. When copper sheets were coated with the hybrid matrix with or without GF70 ( $1 \mathrm{C}$ and $2 \mathrm{~A}$ ) the change in color was not detectable with human eye, i.e. $\Delta \mathrm{E}<3$, pointing out that the hybrid coating ( $3 \mathrm{~A}$ ) itself exerts a barrier effect on it. But the incorporation of Si69 into the hybrid matrix deteriorates this effect, i.e. $\Delta \mathrm{E}>>3$. Its cause was not investigated since it was out of scope of this study.

Table 3: The color coordinates and $\Delta \mathrm{E}$ values of coatings $1 \mathrm{C}, 2 \mathrm{~A}$ and $3 \mathrm{~A}$ before and after

\begin{tabular}{|c|c|c|c|c|c|c|c|}
\hline \multirow{3}{*}{ Sample } & \multicolumn{6}{|c|}{ Color coordinates } & \multirow{3}{*}{$\Delta \mathrm{E}$} \\
\hline & \multicolumn{3}{|c|}{ Before irradiation } & \multicolumn{3}{|c|}{ After irradiation } & \\
\hline & $\mathbf{L}$ & $\mathbf{a}$ & b & $\mathbf{L}$ & $\mathbf{a}$ & b & \\
\hline Uncoated & 51.4 & 10 & 21.2 & 55.0 & 9.7 & 20.1 & 5.5 \\
\hline $1 \mathrm{C}$ & 27.2 & 9.1 & 26.6 & 29.3 & 9.2 & 26.8 & 2.1 \\
\hline $2 \mathrm{~A}$ & 53.6 & 12.7 & 33.3 & 54.2 & 13.8 & 34.9 & 2.0 \\
\hline $3 \mathrm{~A}$ & 35.5 & 10.6 & 38.3 & 36.7 & 9.8 & 33.5 & 5.0 \\
\hline
\end{tabular}

In adhesion test, after scratching the coating surface with a multi-cutter knife, a standard tape is stuck and peeled off. The amount of coating that has been peeled off along with the tape is determined and the adhesion of the coating is graded according to the given standard. Both studied primary and top-coat layers showed no disintegration and had excellent adhesion and (i.e. 5B meaning $0 \%$ peel off) to the surface of copper substrate (see Table 4). As given in Table 4, the bare copper sheet has a soft surface. The application of primary layers only, i.e. $2 \mathrm{C}$ and $3 \mathrm{C}$, on copper sheet hardly changed its hardness. As it was coated with hybrid matrix only, its pencil hardness was hugely increased to the highest value of the scale of the test method, i.e. $9 \mathrm{H}$. The incorporation of thiol functional silanes into the hybrid matrix lowered its pencil hardness down to the grade $8 \mathrm{H}$, since the share of epoxy functional silane (GLYMO) in their coatings was decreased. 
Table 4. The results of tests of hardness and adhesion of all coatings studied.

\begin{tabular}{|c|c|c|c|c|}
\hline & \multirow{2}{*}{ Samples } & \multicolumn{2}{|c|}{ Hardness } & \multirow[t]{2}{*}{ Adhesion Tests } \\
\hline & & Newton (N) & Pencil & \\
\hline \multicolumn{2}{|r|}{ Uncoated } & 0.1 & 4B & - \\
\hline $1 \mathrm{~A}$ & Hybrid matrix+GF70 & 1.7 & $8 \mathrm{H}$ & 5B \\
\hline $1 \mathrm{~B}$ & Hybrid matrix+Si69 & 1.8 & $8 \mathrm{H}$ & $5 B$ \\
\hline $1 \mathrm{C}$ & Hybrid matrix & 2.1 & $9 \mathrm{H}$ & $5 B$ \\
\hline $2 \mathrm{~A}$ & GF70 Primer + Hybrid matrix+GF70 & 1.8 & $8 \mathrm{H}$ & $5 B$ \\
\hline $2 B$ & GF70 Primer + Hybrid matrix & 2 & $9 \mathrm{H}$ & $5 B$ \\
\hline $2 \mathrm{C}$ & GF70 Primer & 0.5 & $4 \mathrm{~B}$ & $5 B$ \\
\hline $3 \mathrm{~A}$ & Si69 Primer + Hybrid matrix+Si69 & 1.8 & $8 \mathrm{H}$ & $5 B$ \\
\hline $3 B$ & Si69 Primer + Hybrid matrix & 1.8 & $8 \mathrm{H}$ & $5 B$ \\
\hline $3 C$ & Si69 Primer & 0.5 & $4 B$ & $5 B$ \\
\hline
\end{tabular}

When all coatings were exposed to the solutions of $\mathrm{HNO}_{3}$ at $\mathrm{pH}=2$ and of $\mathrm{NaOH}$ at $\mathrm{pH}=12$ separately, there visually was no damage on the surface of the coated samples.

Pictures of the uncoated copper substrate, coatings $1 \mathrm{~A}, 1 \mathrm{~B}, 2 \mathrm{~A}$ and $3 \mathrm{~A}$ are given in Figure 3. In the salt spray test, bare copper sheet already started to corrode after the first day of testing. As the copper sheet coated with the hybrid matrix comprising Si69, i.e. 1B, partly withstood corrosion up to 7 days, the substrate with both Si69 primary layer and hybrid matrix comprising Si69, i.e. 3A, failed, where its color became black-ish. This observation indicates that tetrasulfide groups on Si69 degrade very fast under test conditions (25) producing sulfide ions which, in turn, react with copper ions released from the surface of copper to form blackcolored copper sulfide. When the hybrid matrix with GF20, i.e. 1A, was applied onto copper sheet, it considerably resisted corrosion up to 7 days. As G70 primary layer and hybrid matrix comprising $\mathrm{G} 70$, i.e. $2 \mathrm{~A}$, it resisted corrosion up to 30 days as tested. The fact that the discoloration started from the edge area of all coated substrates and the obtained coatings were smooth and, pinhole- and crack-free suggests that the corrosion happens due to the diffusion of $\mathrm{NaCl}$ under the coating layer through the uncoated part of the sample towards the middle of the coated surface. 


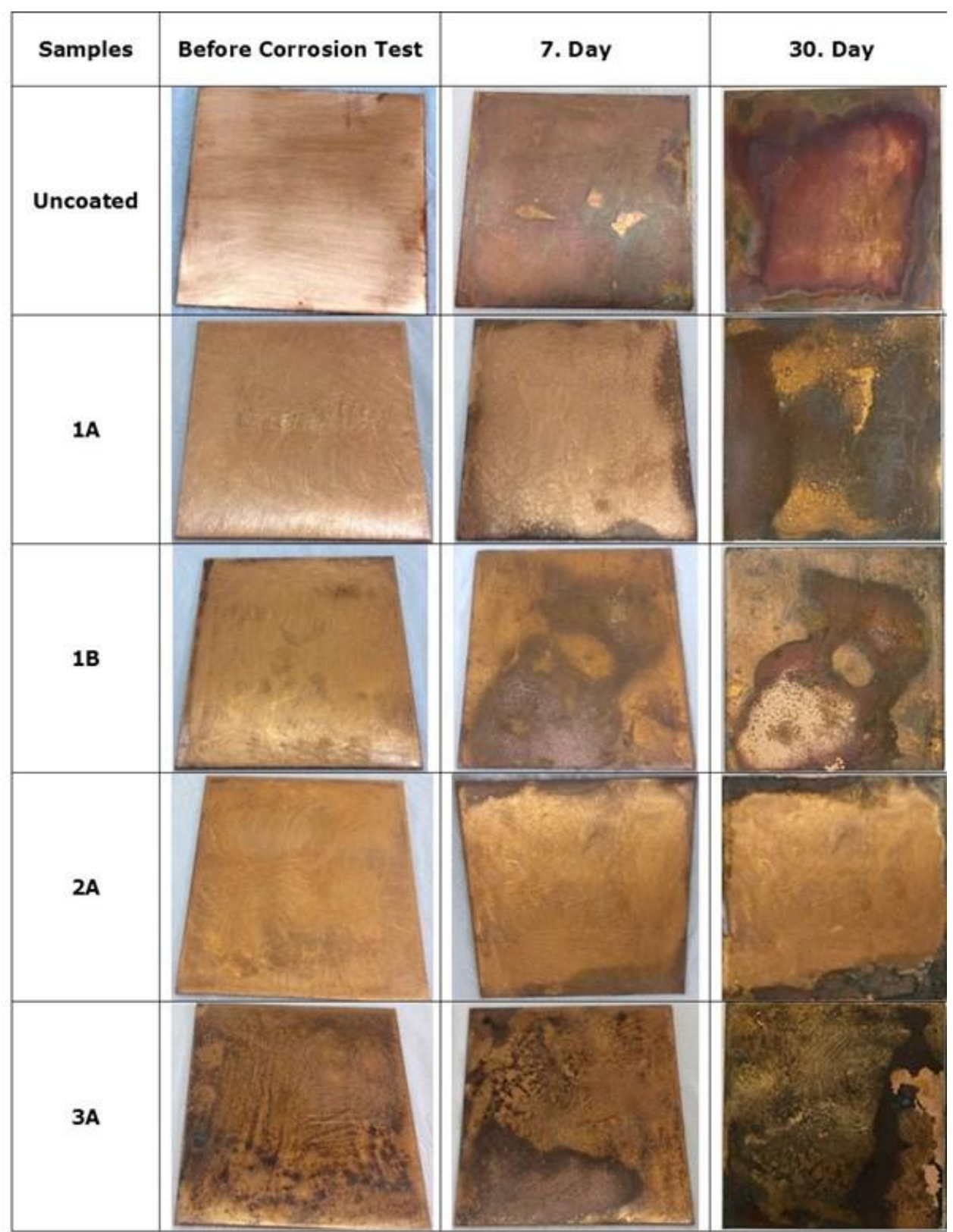

Figure 3: The pictures of uncoated copper and coated with $1 \mathrm{~A}, 1 \mathrm{~B}, 2 \mathrm{~A}$ and $3 \mathrm{~A}$ before and after the salt spray test.

To determine its transparency quantitatively, a glass substrate was applied with the coating 2A since copper does not transmit the light. The transmittance spectra of the uncoated glass substrate and the coated glass substrate coated with the sample $2 \mathrm{~A}$ in UV-Vis range are shown in Figure 4. The coating of glass with the sample 2A causes no loss in its transparency indicating the applied layers have same optical properties with the substrate. 


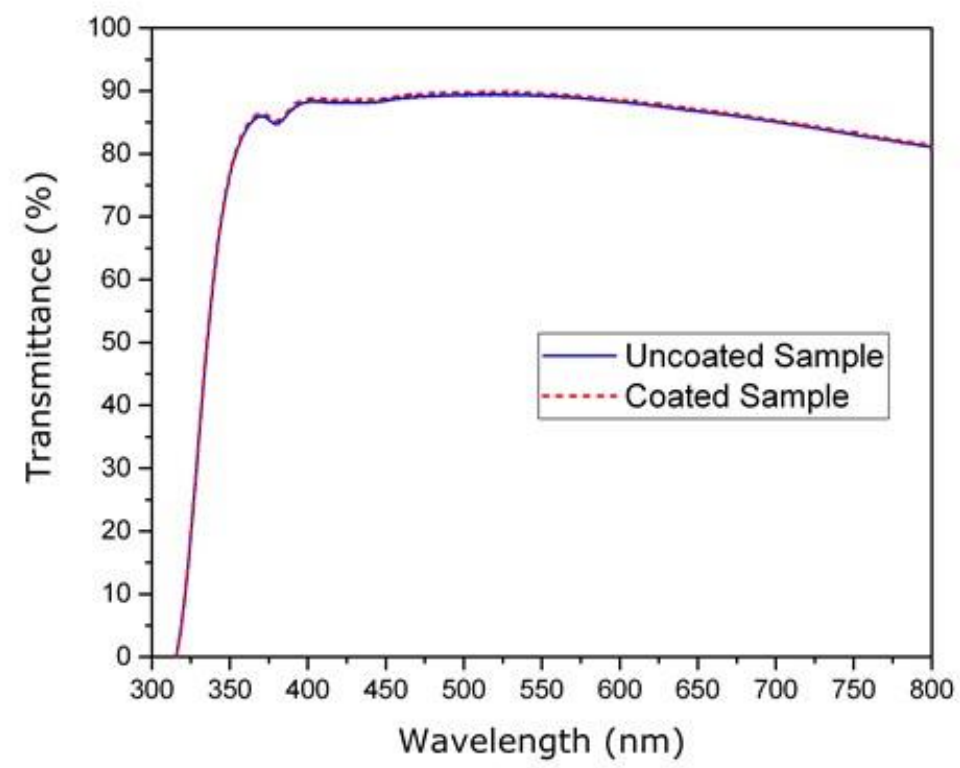

Figure 4: The UV-Vis spectra of uncoated glass and glass coated with the sample $2 \mathrm{~A}$.

\section{CONCLUSION}

In this study, highly transparent hybrid coatings comprising thiol functional silane on copper sheet are obtained by sol-gel chemistry. The mechanical toughness of bare copper sheet is immensely improved by coating it with the sole hybrid matrix. As the hybrid matrix was incorporated with GF70, it withstood corrosion up to 7 days. The corrosion resistance was extended up to 30 days as tested when a primary layer of GF20 was applied onto copper sheet prior to its coating of hybrid matrix with GF20. The coating developed in this study is readily applicable for indoor and outdoor uses to prolong the life span of copper-based materials, since it has high UV-resistance and is durable both chemically and mechanically.

\section{ACKNOWLEDGEMENTS}

Authors would like to thank Akdeniz University Research Fund for financial support. Technical and financial support of NANOen is gratefully acknowledged.

\section{REFERENCES}

1. Fan Y, Li C, Chen Z, Chen H. Study on fabrication of the superhydrophobic sol-gel films based on copper wafer and its anti-corrosive properties. Appl Surf Sci. 2012 2012/06/15/;258(17):6531-6.

2. Muñoz AI, Antón JG, Guiñón JL, Herranz VP. Comparison of inorganic inhibitors of copper, nickel and copper-nickels in aqueous lithium bromide solution. Electrochimica Acta. 2004 2004/12/15/;50(4):957-66. 
3. Biswas BN, Mollah MYA, Susan MABH. Potentiodynamic studies on corrosion of copper by chloride ions and its inhibition by inorganic and organic ions in aqueous buffer solution. Ionics. 2012 January 01;18(1):189-95.

4. Antonijevic MM, Petrovic MB. Copper corrosion inhibitors. A review. Int J Electrochem Sci. 2008 Jan;3(1):1-28. PubMed PMID: WOS:000256383600001. English.

5. Sherif EM, Park S-M. 2-Amino-5-ethyl-1,3,4-thiadiazole as a corrosion inhibitor for copper in 3.0\% $\mathrm{NaCl}$ solutions. Corrosion Science. 2006 2006/12/01/;48(12):4065-79.

6. Sherif EM, Park S-M. Effects of 2-amino-5-ethylthio-1,3,4-thiadiazole on copper corrosion as a corrosion inhibitor in aerated acidic pickling solutions. Electrochimica Acta. 2006 2006/09/15/;51(28):6556-62.

7. Sherif E-SM. Effects of 2-amino-5-(ethylthio)-1,3,4-thiadiazole on copper corrosion as a corrosion inhibitor in 3\% NaCl solutions. Appl Surf Sci. 2006 2006/10/15/;252(24):8615-23.

8. Stupnis ek-Lisac E, Brnada A, Mance AD. Secondary amines as copper corrosion inhibitors in acid media. Corrosion Science. 2000 2000/02/01/;42(2):243-57.

9. Ma H, Chen S, Niu L, Zhao S, Li S, Li D. Inhibition of copper corrosion by several Schiff bases in aerated halide solutions. Journal of Applied Electrochemistry. 2002 January 01;32(1):65-72.

10. Ehteshamzade M, Shahrabi T, Hosseini MG. Inhibition of copper corrosion by self-assembled films of new Schiff bases and their modification with alkanethiols in aqueous medium. Appl Surf Sci. 2006 2006/02/15/;252(8):2949-59.

11. Matos JB, Pereira LP, Agostinho SML, Barcia OE, Cordeiro GGO, D'Elia E. Effect of cysteine on the anodic dissolution of copper in sulfuric acid medium. Journal of Electroanalytical Chemistry. 2004 2004/08/15/;570(1):91-4.

12. Moretti G, Guidi F. Tryptophan as copper corrosion inhibitor in $0.5 \mathrm{M}$ aerated sulfuric acid. Corrosion Science. 2002 2002/09/01/;44(9):1995-2011.

13. Gasparac R, Martin CR, Stupnisek-Lisac E. In situ studies of imidazole and its derivatives as copper corrosion inhibitors - I. Activation energies and thermodynamics of adsorption. J Electrochem Soc. 2000 Feb;147(2):548-51. PubMed PMID: WOS:000085294400023. English.

14. Bastidas JM, Lopez-Delgado A, Cano E, Polo JL, Lopez FA. Copper corrosion mechanism in the presence of formic acid vapor for short exposure times. J Electrochem Soc. 2000 Mar;147(3):9991005. PubMed PMID: WOS:000085912700028. English. 
Akarsu and Kesmez, JOTCSA. 2017; 4(sp. is. 1): 65-76.

15. Papapanayiotou D, Nuzzo RN, Alkire RC. Adsorption of thiourea on copper electrodes monitored by in situ infrared spectroscopy. J Electrochem Soc. 1998 Oct;145(10):3366-73. PubMed PMID: WOS:000076217000009. English.

16. Quartarone G, Moretti G, Bellomi T, Capobianco G, Zingales A. Using indole to inhibit copper corrosion in aerated 0.5 M sulfuric acid. Corrosion. 1998 Aug;54(8):606-18. PubMed PMID: WOS:000075196800004. English.

17. Stein N, Johann L, Rapin C, Lecuire JM. In-situ ellipsometric study of copper passivation by copper heptanoate through electrochemical oxidation. Electrochimica Acta. 1998 1998/07/01/;43(21):322734.

18. Feng YQ, Teo WK, Siow KS, Gao ZQ, Tan KL, Hsieh AK. Corrosion protection of copper by a selfassembled monolayer of alkanethiol. J Electrochem Soc. 1997 Jan;144(1):55-64. PubMed PMID: WOS:A1997WG07000014. English.

19. Liang C, Wang P, Wu B, Huang N. Inhibition of copper corrosion by self-assembled monolayers of triazole derivative in chloride-containing solution. Journal of Solid State Electrochemistry. 2010 August 01;14(8):1391-9.

20. Sui W, Zhao W, Zhang X, Peng S, Zeng Z, Xue Q. Comparative anti-corrosion properties of alkylthiols SAMs and mercapto functional silica sol-gel coatings on copper surface in sodium chloride solution. Journal of Sol-Gel Science and Technology. 2016 November 01;80(2):567-78.

21. Figueira R, Fontinha I, Silva C, Pereira E. Hybrid Sol-Gel Coatings: Smart and Green Materials for Corrosion Mitigation. Coatings. 2016;6(1):12. PubMed PMID: doi:10.3390/coatings6010012.

22. Budakoglu R, Arpac E. Synthesis of inorganic-organic polymers. In: Mandal $H$, Ovecoglu $L$, editors. Euro Ceramics Viii, Pts 1-3. Key Engineering Materials. 264-268. Zurich-Uetikon: Trans Tech Publications Ltd; 2004. p. 423-6.

23. Tatar P, Kiraz N, Asiltürk M, Sayılkan F, Sayılkan H, Arpaç E. Antibacterial Thin Films on Glass Substrate by Sol-Gel Process. Journal of Inorganic and Organometallic Polymers and Materials. 2007 September 01;17(3):525-33.

24. New Test Method for Optical Imaging Evaluation of Adhesion by Tape Test Specimens, ASTM D 3359 WK97

25. Caprioli F, Martinelli A, Gazzoli D, Di Castro V, Decker F. Enhanced Protective Properties and Structural Order of Self-Assembled Monolayers of Aromatic Thiols on Copper in Contact with Acidic Aqueous Solution. The Journal of Physical Chemistry C. 2012 2012/02/23;116(7):4628 36. 